\title{
Aflavinines: History, Biology and Total Synthesis
}

\author{
Dirgha Raj Joshi ${ }^{1, \otimes}$, Nisha Adhikari ${ }^{2}$
}

Received: 21 February 2020 / Accepted: 03 March 2020 / Published Online: 13 March 2020

(C) SAMI Publishing Company (SPC) 2020

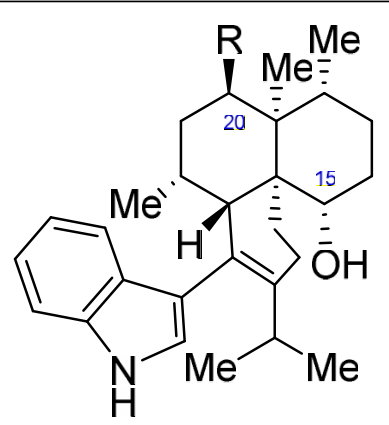

Aflavinine (1): $\mathrm{R}=\mathrm{H}$

20-Hydroxyaflavinine

(2): $\mathrm{R}=\mathrm{OH}$

\section{ABSTRACT}

This review aims to provide overall aspects of the history, biology, chemistry and the total synthesis of Aflavinines. The origin of this molecule traced back from the isolation and structural elucidation by Clardy and co-workers in 1980 [Tetrahed. Lett. 1980;21:243246]. Most of the previously published total syntheses were covered in a brief summary and the key points of each work are highlighted. Moreover, various antiinsectant and antiviral Aflavinines congener are presented. This review is almost the first in Aflavinine topics covering all aspects in brief, to the best of our knowledge.

Keywords: Aflavinine; Antiinsectant; Epoxyeujindole-A; Aflavazole; HydroxyAflavinine; Tubingensin-A.

\section{Introduction}

Aflavinine (panel 1 of Fig 1., colorless needles, m.p. $102^{\circ} \mathrm{C}$ ) an indolditerpene, is a fascinating molecule having remarkable history traced back to 1980 when the Clardy and co-workers first time did isolation from sclerotia of Aspergillus flavus and elucidated the structure of it (Fig 1, different Aflavinines) [1]. Its biological activities and various applications have been studied over time, which are reviewed here in brief. Following the isolation and determination of Aflavinine structure, further efforts have been dedicated to explore the biological activity and to discover various

\footnotetext{
$\triangle$ Corresponding author.

E-mail address: djmeropaila121@korea.ac.kr (D.R. Joshi)

${ }^{1}$ College of Pharmacy, Yonsei University, Yeonsu-gu, Incheon, Republic of Korea
}

Aflavinine congeners. Following the structure elucidation, some total synthesis approaches have been done, which are covered here in brief. Its isolation, structure elucidation, biological activity, synthetic approach and a brief overview of its chemistry are summarized. Although the major biological activity has been identified as antiinsectant [2-7], other biological activities focusing on the antiviral and anticancer agents are discussed here. We hope that the current critical review will energize the researchers to catch the up-to-date information about Aflavinine history, its chemistry, biology, and recent achievements to

\footnotetext{
${ }^{2}$ College of Pharmacy, Gachon University, Yeonsu-gu, Incheon, Republic of Korea
} 
explore further potential activities of this for possible applications in further drug discovery interesting and synthetically challenging molecule purposes.

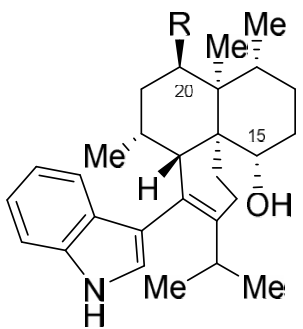

Aflavinine (1): $\mathrm{R}=\mathrm{H}$ 20-Hydroxyaflavinine (2): $\mathrm{R}=\mathrm{OH}$

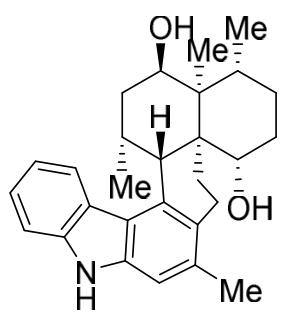

Aflavazole (5)

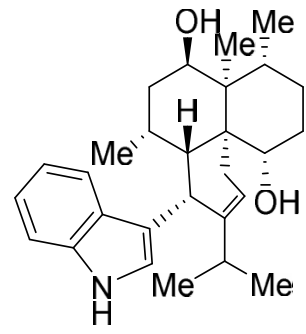

10,11-Dihydro-11,12-Dehydro20-Hydroxyaflavinine (3)

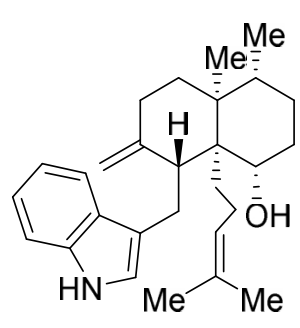

Anominine (6)

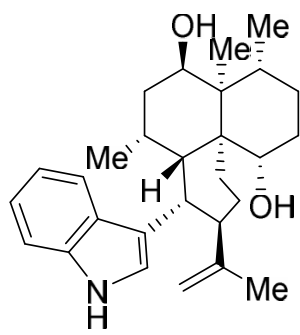

24,25-Dehydro-10,11-Dihydro20-Hydroxyaflavinine (4)

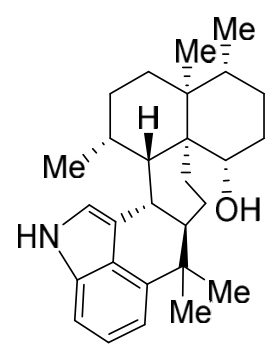

17-Hydroxyeujindole (7)

Fig. 1. Some selected aflavinine family members

\section{Summary Timeline of Total Synthesis}

- In 1980: Clardy and co-workers did isolation of Aflavinine from sclerotia of Aspergillus flavus and elucidated its structure for the first time.

- In 1985: Danishefsky and co-workers reported total synthesis of 3-desmethyl Aflavinine via $[2+2+2]$ annulation for the first time.

- In 2012: Li and co-workers did total synthesis of anominine and its congener tubingensin $A$.

- In 2015/16: Li and co-workers unified total synthesis of Aflavinine family (epoxyeujondole A, 20-hydroxy Aflavinine (renamed to 14hydroxy Aflavinine), and aflavazole).

- In 2019: Kwak and co-workers found the approach to access the structural core of Aflavinine.

\section{Materials and Methods}

PubMed, Google Scholar, Hinari, Semantic Scholar, World Cat and Worldwide Science, and some more of search engines are screened with the key word 'Aflavinine' to find the up-to-date information from its first appearance in literature in 1975 up to 2020 March 02.

\section{Historical Aspects and its Chemistry}

After discovery of Aflavinine in 1980 [1], various structurally varied congeners were discovered by Gloer and co-workers from Aspergillus, which include 10,11-dihydro-11,12-dehydro-20-hydroxy Aflavinine, 24,25-dehydro-10,11-dihydro-20hydroxy Aflavinine, aflavazole and anominine (panels 3-6 of Fig. 1) [3-5, 8-10]. Nakadate and coworkers reported 17-hydroxyeujindole (panel 7 of Fig. 1) and its dehydrated congener having a different ring fusion pattern [11-12]. Except for the anominine (panel 6 of Fig. 1), most of the Aflavinine family has a similar pattern of a tightly fused tricyclic framework with six or seven stereogenic centers having two vicinal quaternary carbons. The general numbering of Aflavinine is shown in Fig. 2 [3]. Throughout time, various Aflavinine congener were identified and reported $[4,8,10,13,14]$. Due to densely fused ring system 
with 6 to 7 stereogenic centers, it becomes a considerable challenge to synthetic chemist to mostly put the hydroxyl group to the $\mathrm{C}(15)$ and $C(20)$ adjacent positions to the vicinal quaternary centers. This intricate structure has anticancer and antiviral potency but mostly limited to antiinsectant $[3,5,15,16]$. To this date, the synthetic challenges have been arisen to supply easily through commercial production due to the poor supply of Aflavinine from natural products. The chemistry and biology of the mycotoxin and other related fungal metabolites are discussed by Stefan and co-workers in their review work [17]. Comparing the chemistry of Aspergillus flavus and Aspergillus Oryzae was discussed by Rank and coworkers [18]. The studies on sclerotia of some species of Aspergillus genus was discussed by Soudo and co-workers [19]. Other various secondary metabolites of Aspergillus flavus are also discussed in the literature $[20,21]$.

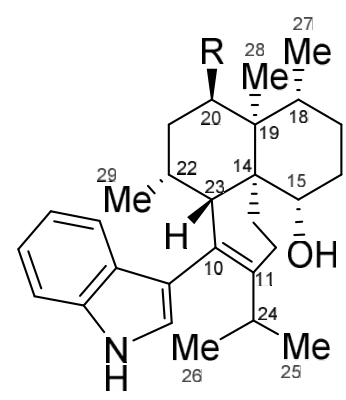

Aflavinine (1): $\mathrm{R}=\mathrm{H}$

20-Hydroxyaflavinine

(2): $\mathrm{R}=\mathrm{OH}$

Fig. 2. Numbering of Aflavinines

\section{Biology of Aflavinine and its Congener}

Although the major biology activity of Aflavinine is tested for antiinsectant activity [2-7], some antiviral potencies are also reported. In 1988, Gloer and co-workers published a work of four antiinsectant Aflavinine derivatives (20,25Dihydroxy Aflavinine, 20-Hydroxy Aflavinine, 24,25-Dehydro-10,11-dihydro-20-hydroxy

Aflavinine, and 10,11-Dihydro-11,12-dehydro-20hydroxy Aflavinine) from the sclerotia of Aspergillus flavus against, a common crop insect
Carpophilushemipterus [3]. Furthermore, Gloer isolated a biological species related to Aflavinine; tubingensin A, from sclerotia of the fungus Aspergillus Tubingensis in 1989 . This exhibits potent activity against the various crop pest Heliothiszea and also shows in vitro antiviral potency against type 1 herpes simplex virus [9]. Antiinsectant carbazole metabolite and aflavazole from Aspergillus flavus were reported in 1990 by Gloer and co-workers [4]. They also isolated the new antiinsectant metabolites, Aflavarin and $\beta$ aflatrem from Aspergillus flavus in 1992 [6]. Similarly, other antiinsectant and antiviral Aflavinines were reported by Gloer and coworkers [5, 7-9]. The Antiinsectan effects of various Aspergillus metabolites are discussed by Gloer and co-workers [15]. These are few examples showing some Aflavinines with antiinsectant and antiviral properties. For more details, the individual Aflavinine congeners are needed to be investigated.

\section{Total Synthesis of Aflavinine and its Congener}

The attraction to this Aflavinine and its family members is not due to its structure only but having potency from a biological point of view, which is always in the first line. Here the total synthesis of Aflavinine and its congener up to now are discussed.

\section{The First Total Synthesis by Danishefsky and coworkers in 1985}

The first total synthesis of 3- desmethyl Aflavinine, an Aflavinine analogous, was reported by Danishefsky and co-workers for the first time in 1985 (Fig. 3.) [22]. The key highlight in its synthesis is the one-pot process via $(2+2+2)$ annulation to make a sterically congested tricyclic framework. Due to undesired stereochemical outcomes at $\mathrm{C}(4)$ position, this method of synthesis to natural Aflavinine (panel 1 of Fig. 1) was unsuccessful [2224]. 


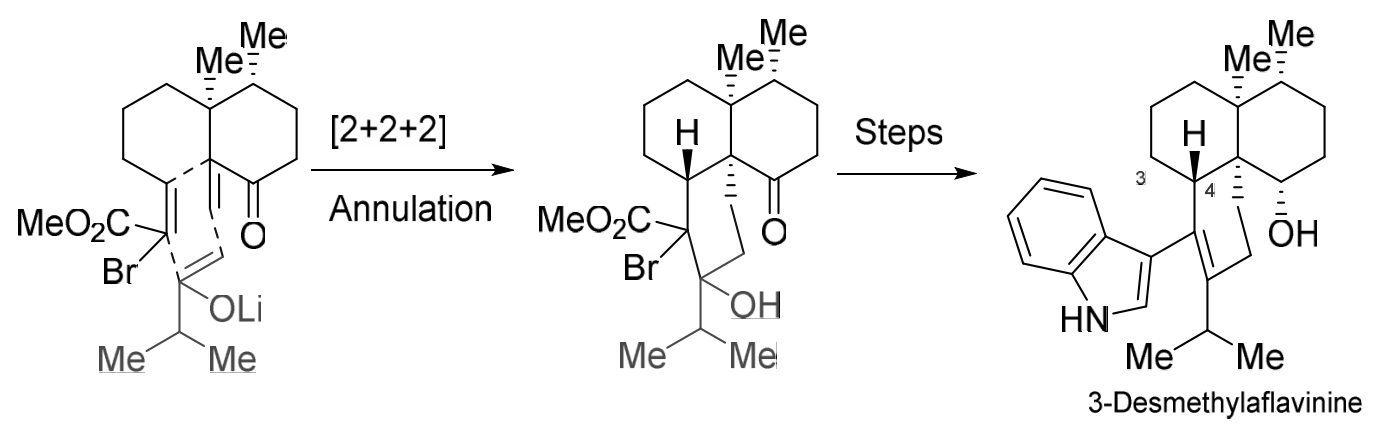

Fig. 3. Synthesis of 3-Desmethylaflavinine via a [2+2+2] Annulation by Danishefsky

\section{Unified Total Synthesis of Aflavinine Family by Li} and Co-workers in 2015/16

Over 30 years after the first total synthesis, Li and co-workers reported the total syntheses of 8,21dehydro-17,20-epoxyeujondole A (panel 8 of Fig. 4 ) in 2015 [25]. They reported total synthesis of 20-Hydroxy Aflavinine (panel 2 of Fig. 1) (renamed to 14-hydroxy Aflavinine for making it consistent with the unified numbering system of the anominine family) and aflavazole (panel 5 of Fig. 4) in 2016 [26]. In this total synthesis, they developed a common strategy to get access to these natural compounds via a common precursor, tricyclic acetal using a key step $\mathrm{All}_{3}$-promoted alkyne Prins cyclization or acid-promoted late-stage cationic cyclization to form the sterically congested polycyclic ether frameworks. During this long lacking period, another biology testing has been done through obtaining various Aflavinine congeners from a natural source and the feasibility of Aflavinine synthesis via theoretical and experimental studies [27, 28].

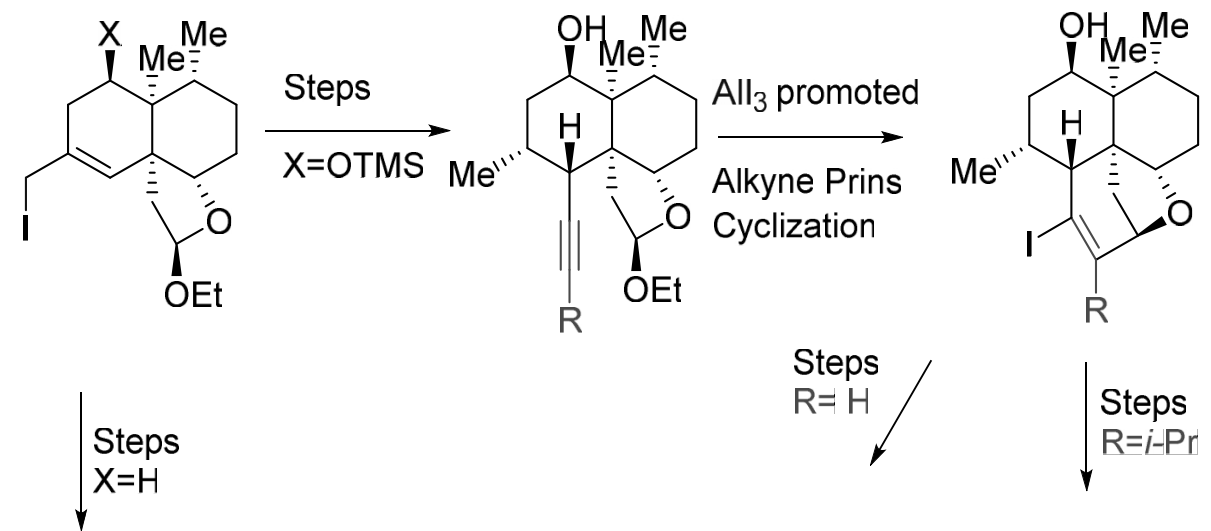

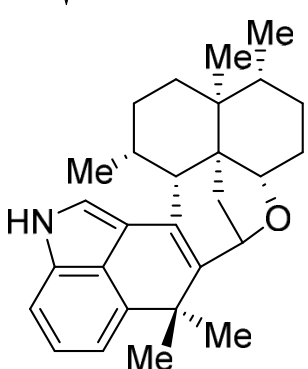

Epoxyeujindole A (8)

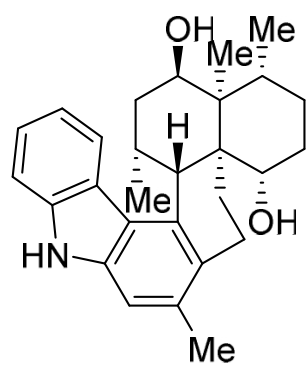

Aflavazole (5)

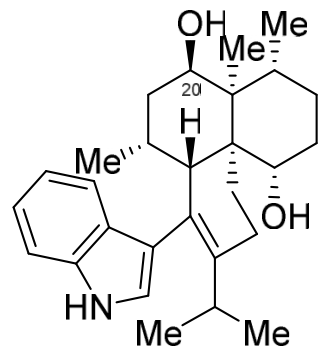

20-Hydroxyaflavinine (2)

Fig. 4 Unified total synthesis of Aflavinine family via Acid-Promoted cyclization by Li and Coworkers

Total Synthesis of Anominine and its Congener Tubingensin A by Li and Co-workers in $\mathbf{2 0 1 2}$

The total synthesis of anominine (panel 6 of Fig. 1) and its congener tubingensin $A$ (panel 9 of Fig. 5), a parent molecule of Aflavinine family were reported by Li and co-workers in $2012[29,30]$ Here they are able to synthesize the anominine and tubingensin from the common intermediate 
(Fig. 5) that have all needed stereogenic centers. They first assembled the key intermediate via employing the $\mathrm{Sc}(\mathrm{OTf})_{3}$-mediated Mukaiyama aldol reaction and Ueno-Stork radical cyclization process to construct the stereocontrolled C-C bonds. The way to form tubingensin A follows a CuOTf-promoted $6 \pi$-electrocyclization to form the core of pentacyclic scaffold whereas for the synthesis of anominine employ a radical deoxygenation then installation of side-chain [30].

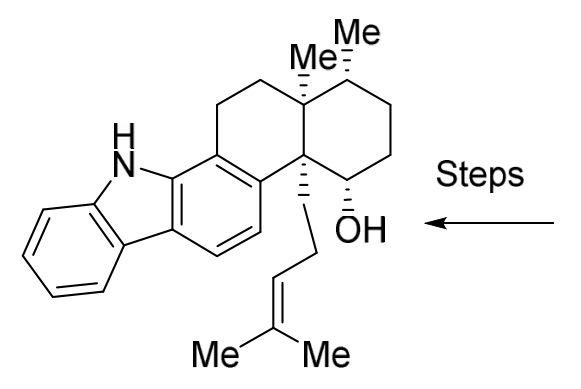

Tubingensin $A(\mathbf{9})$<smiles>C[C@H]1CC(CC(=O)O[Na])CCC1=O</smiles><smiles>CCOC(C)O[C@H]1CCC(C)C2(C)CCC(=O)C[C@]12C</smiles>

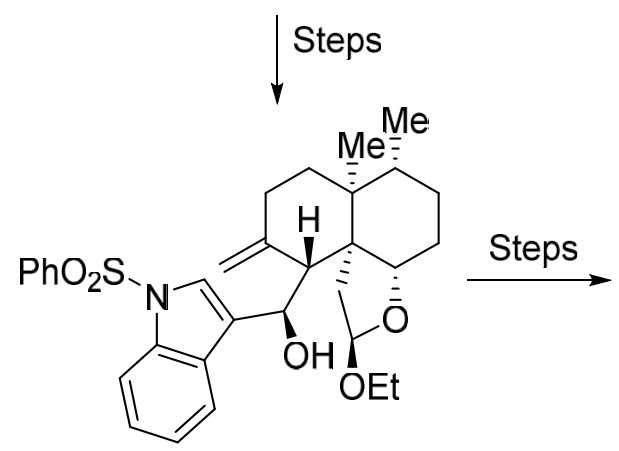

Key intermediate<smiles>C=C1CCC2(C)C(C)CCC[C@H](O)C2C1(CC)CCC=C(C)C</smiles>

Anominine (6)

Fig. 5. Total Syntheses of Anominine (6) and Tubingensin A (9)

\section{Approach by Kwak and Co-workers to Reach to the Core of Aflavinine Framework}

The Goldberg and co-workers reported a tandem intramolecular Diels-Alder cycloaddition involving alkynone connected with two 1,3-butadienes under Lewis acid-promoted reaction conditions [31]. This achievement was applied by Kwak and co-workers to reach to the core of Aflavinine synthesis where they used the intramolecular Diels-Alder cycloaddition concept between the two distinct electron-rich furan rings linked with electron-deficient alkyne dienophile (Fig. 6) [32]. The stereocontrol was achieved via protecting the free alcohol by bulky TIPS (triisopropylsilyl) group, which promotes the allylic1,3-strain and favors the key cycloaddition step. The structural chemistry of this Aflavinine core shows an excellent way of making various synthetic analogs due to having a functional group and other various substituting sites.<smiles>CON(C)C(=O)c1occc1C</smiles>

Fig. 6 Synthesis of structural core of Aflavinines via Tandem intramolecular Diels-Alder cycloaddition

\section{Conclusion}

From this summarized review, it is clear that achieved total synthesis, going on the total synthesis, reported biological activity and further testing approach makes its increasing interest to researchers. The period of 39 years on Aflavinine history from its discovery in 1980 to date shows a long lacking period from the first total synthesis 
approach to the second total synthesis, but its biological point of view is increasing especially to its various congeners and various analog are isolating from natural sources. The structural complexity of Aflavinine is a reason why its synthesis is delayed and all approaches are not yet enough to supply it in a commercial way. However, the story hidden behind the total synthesis of Aflavinine might also be an appreciating reflection showing progress in view of the art and craft of

\section{References}

1. Gallagher RT, McCabe T, Hirotsu K, Clardy J, Nicholson $\mathrm{J}$, Wilson BJ. Aflavinine, a novel indole-mevalonate metabolite from tremorgen-producing aspergillusflavus species. Tetrahed. Lett. 1980;21:243246.

2. Wicklow DT. Role of fungal sclerotia in the epidemiology of aspergillus flavus in maize. JSM Mycotox. 1988;1988:155-158.

3. Gloer JB, TePaske MR, Sima JS, Wicklow DT, Dowd PF. Antiinsectan aflavinine derivatives from the sclerotia of aspergillus flavus. J. Org. Chem. 1988;53:5457-5460.

4. TePaske MR, Gloer JB, Wicklow DT, Dowd PF. Aflavazole: a new antiinsectan carbazole metabolite from the sclerotia of aspergillus flavus. J. Org. Chem. 1990;55:5299-5301.

5. Gloer JB. Antiinsectan natural products from fungal sclerotia. Acc. Chem. Res. 1995;28:343-350.

6. TePaske MR, Gloer JB, Wicklow DT, Dowd PF. Aflavarin and $\beta$-Aflatrem: new anti-insectan metabolites from the sclerotia of aspergillus flavus. J. Nat. Prod. 1992;55:1080-1086.

7. Wang H-J, Gloer JB, Wicklow DT, Dowd PF. Aflavinine s and other antiinsectan metabolites from the ascostromata of eupenicillium crustaceum and related species. Appl. Environ. Microbiol. 1995;61:4429-4435.

8. Gloer JB, Rinderknecht BL, Wicklow DT, Dowd PF. Nominine: a new insecticidal indole diterpene from the sclerotia of aspergillus nomius. J. Org. Chem. 1989;54:2530-2532.

9. TePaske MR, Gloer JB, Wicklow DT, Dowd PF. Tubingensin A: an antiviral carbazole alkaloid from the sclerotia of aspergillus tubingensis. J. Org. Chem. 1989;54:4743-4746.

10. TePaske MR, Gloer JB, Wicklow DT, Dowd PF. Three new aflavinines from the sclerotia of Aspergillus tubingensis. Tetrahed. 1989;45:4961-4968. organic synthesis. We, the authors, hope that the potential readers of this concise review will find a new and ambitious synthetic way to Aflavinine, which is really a fascinating potential molecule.

\section{Acknowledgements}

We heartily acknowledge Yonsei University, College of Pharmacy and Gachon University, College of Pharmacy for providing space and essential things to prepare this manuscript.

11. Nakadate S, Nozawa K, Horie H. New type indole diterpene, eujindoles, from eupenicillium javanicum. Heterocycl. 2011;83:351-356.

12. Nakadate $S$, Nozawa K, Yaguchi T. Two new eujindoles from Eupenicillium javanicum. Nat. Prod. Update. 2011;83:1867-1871.

13. Nozawa K, Sekita S, Harada M, Udagawa S, Kawai K. Isolation and structures of two new indoloditerpenes related to aflavinine from a microsclerotium-producing strain of aspergillus flavus. Chem. Pharm. Bull. 1989;37:626-630.

14. TePaske MR, Gloer JB, Wicklow DT, Dowd PF. The structure of tubingensin B: A cytotoxic carbazole alkaloid from the sclerotia of aspergillustubingensis. Tetrahed. Lett. 1989;30:5965-5968.

15. Wicklow D, Dowd P, Gloer J. Antiinsectan effects of aspergillus metabolites. The genus Aspergillus. Springer; 1994. p. 93-114.

16. Laakso JA, TePaske MR, Dowd PF, Gloer JB, Wicklow DT, Staub GM. Indole antiinsectan metabolites. Google Patents; 1993.

17. Brase S, Encinas A, Keck J, Nising CF. Chemistry and biology of mycotoxins and related fungal metabolites. Chem. Rev. 2009;109:3903-3990.

18. Rank C, Klejnstrup ML, Petersen LM, Kildgaard S, Frisvad JC, Held Gotfredsen C, et al. Comparative chemistry of aspergillus oryzae (RIB40) and A. flavus (NRRL 3357). Metabol. 2012;2:39-56.

19. Abu El-Souod S, Awadalla OA, Assawah SMW, Mahmoud YA-G, El-Debaiky SAE-K. Studies on the sclerotia of some species in the genus aspergillus. Egypt. J. Botan. 2017;57:395-404.

20. Cary JW, Gilbert MK, Lebar MD, Majumdar R, Calvo AM. Aspergillus flavus secondary metabolites: More than just aflatoxins. Food Safety 2018;6:7-32.

21. Uka V, Moore GG, Arroyo-Manzanares N, Nebija D, De 
Saeger SMDG, Diana Di Mavungu J. Secondary metabolite dereplication and phylogenetic analysis identify various emerging mycotoxins and reveal the high intra-species diversity in aspergillus flavus. Front. Microbiol. 2019;10:667.

22. Danishefsky S, Chackalamannil S, Harrison P, Silvestri M. Synthetic studies toward Aflavinine : a synthesis of 3-demethylAflavinine via a $[2+2+2]$ annulation. J. Am. Chem. Soc. 1985;107:2474-2484.

23. Danishefsky $S$, Harrison P, Silvestri M, Segmuller B. A notable stereochemical variation in the $2+2+2$ annulation reaction. J. Org. Chem. 1984;49:1319-1321.

24. Danishefsky S, Chackalamannil S, Silvestri M, Springer J. Stereospecific 2+2+2 annulation. J. Org. Chem. 1983;48:3615-3616.

25. Lu Z, Li H, Bian M, Li A. Total synthesis of epoxyeujindole A. J. Am. Chem. Soc. 2015;137:1376413767.

26. Li H, Chen $Q$, Lu Z, Li A. Total syntheses of aflavazole and 14-hydroxyAflavinine. J. Am. Chem. Soc. 2016;138:15555-15558.
27. Lodge EP. Experimental and theoretical studies in 1,2asymmetric induction: feasibility of a proposed synthesis of aflavinine. University of California, Berkeley; 1988.

28. Herrmann P. Synthetic studies directed toward nitropolyzonamine, aflavinine, and a rigid HMG COA reductase inhibitor. 1995; url: https://elibrary.ru/item.asp?id=5691740

29. Bradshaw B, Etxebarria-Jardí G, Bonjoch J. Total synthesis of (-)-anominine. J. Am. Chem. Soc. 2010;132:5966-5967.

30. Bian M, Wang Z, Xiong X, Sun Y, Matera C, Nicolaou K, et al. Total syntheses of anominine and tubingensin $A$. J. Am. Chem. Soc. 2012;134:8078-8081.

31. Goldberg DR, Hansen JA, Giguere RJ. The tandem intramolecular Diels-Alder reaction. Tetrahed. Lett. 1993;34:8003-8006.

32. Jo M, Lee D, Kwak YS. Rapid access to the structural core of aflavinines via stereoselective tandem intramolecular Diels-Alder cycloaddition controlled by the allylic 1,3-strain. Org. Lett. 2019;21:6529-6533.

How to cite this article: Joshi DR, Adhikari N. Aflavinines: History, Biology and Total Synthesis. Adv. J. Chem. B. 2020;2(1):3-9. doi: 10.33945/SAMI/AJCB.2020.1.2 